\title{
Thương mại là khởi nguồn văn minh
}

\author{
Thượng Tùng
}

29 June 2007

Doanh Nhân Sài Gòn Cuối Tuần

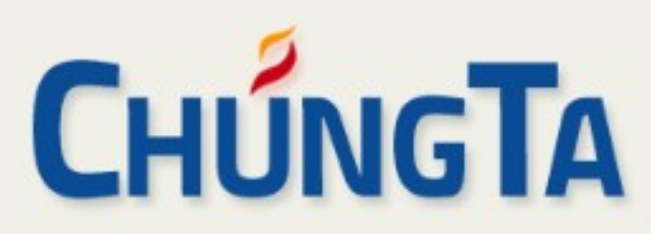

https://www.chungta.com/nd/tu-lieu-tra-cuu/thuong_mai_la_khoi_nguon_van_minh-f.html 


\section{CHÚNGTA}

Trang chủ > Tư liệu nguồn \& tra cứu

\section{Thương mại là khởi nguồn văn minh}

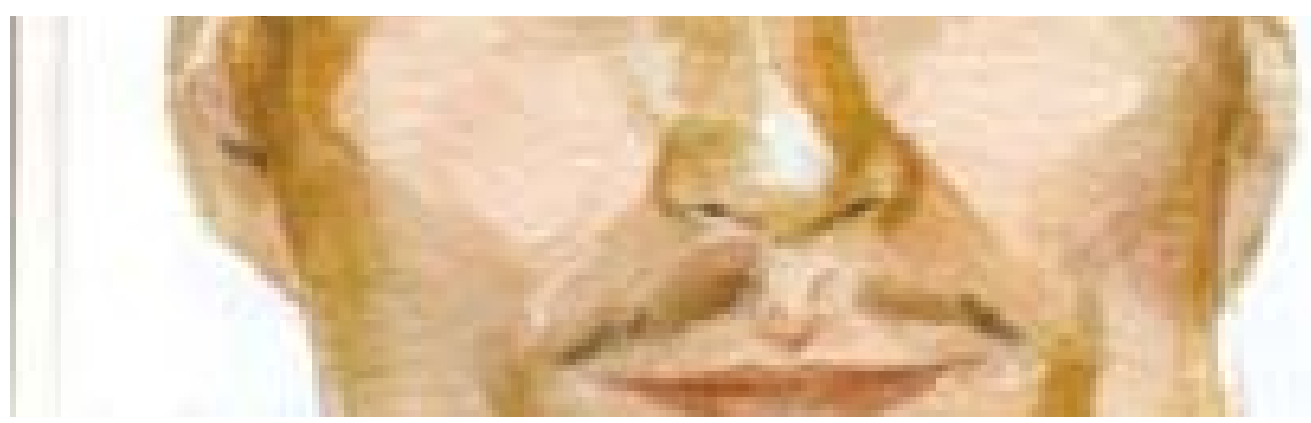

Thượng Tùng (thực hiện)

02:36 CH @ Thứ Sáu - 10 Tháng Tư, 2009

Vương Quân Hoàng bảo vệ luận án tiến sĩ ở Bỉ, là đồng tác giả hai cuốn sách "Nguyên lý tài chính - toán của thị trường chứng khoán " - NXB Chính trị quốc gia - 2000 và "Các phương pháp toán học trong tài chính" - NXB Đại học quốc gia - 2007. Anh đã công bố hàng chục công trình nghiên cứu khoa học trong nước và quốc tế, giữ cương vị ưy viên Ban chấp hành Hội ứng dụng Toán học Việt Nam (từ 2005), thành viên các hiệp hội học thuật Western Finance, European Finance...

Nhìn bản thành tích của anh, người ta dễ liên tưởng đến một người có vẻ bề ngoài không đạo mạo thì cũng "ngơ ngác" một chút. Vậy mà, chót mũi khoặm xuống, hàng ria tót chảy gần sát khóe miệng. Những người lần đầu tiếp xúc rất dễ choáng với các nói chuyện như đang ... diễn thuyết của anh. Mở đầu cuộc trò chuyện, anh đặt lên bàn in thử lần cuối cuốn sách "Văn minh làm giàu \& Nguồn gốc của cải" kèm theo lời bảo chứng "sẽ không thừa một chữ, bởi đã được biên tập đến tám lần."

\section{PV: Có vẻ như anh dã dành nhiều tâm huyết cho "đứa con tinh thần" sắp chào đời?}

Đương nhiên, bạn không có cách gì viết ra được nếu bạn không yêu, không sống với chúng. Tôi còn nhớ khi sắp hoàn thành cuốn sách thì tôi và một số anh em của mình vào TP. Hồ Chí Minh công tác. Tất cả tài liệu và nội dung của cuốn sách đều được lưu trong máy tính xách tay. Trước giờ máy bay cất cánh, tôi đề nghị giao chiếc máy tính ấy cho một người ở lại giữ. Khi hạ cánh an toàn, tôi mới nói cho mọi người biết lý do: đề phòng trường hợp máy bay bị tai nạn. Tôi nghĩ cuốn sách sẽ có ích đối với đối tượng là sinh viên và giảng viên. Cuốn sách này được hoàn thiện trong 14 tháng, dày 460 trang.

Viết một cuốn sách về chuyên môn dễ hơn nhiều, vì người viết thường không giao tiếp với những người không cùng lĩnh vực, cũng như không phải sáng tạo quá nhiều. Thường chỉ lựa chọn và hệ thống lại những kiến thức cần thiết. Nhiều bạn bè đồng nghiệp của tôi đọc qua bản thảo và thừa nhận có nhiều điểm mới, còn một số sinh viên thì tỏ ra rất thích thú sau khi đọc.

PV: Sách về kinh tế thường khó đọc?

Tôi đề cao tuyệt đối tính kiềm chế và khoan hòa. Về mặt nội dung, từng câu chữ trong cuốn sách đều được cân nhắc, kèm theo những ví dụ hài hước để người đọc cảm thấy nhẹ nhàng, dễ tiếp thu. Tôi nghĩ rằng bất kỳ cuốn 
sách nào hàm chứa 10\% xu hướng phục vụ cộng đồng thì đều xứng đáng được vỗ tay. Karl Max nói "Chỉ có súc vật mới quay lưng lại trước nỗi đau của đồng loại để tỉa tót bộ lông của mình". Đạo diễn Đoàn Văn Thủy đã lấy câu nói đó làm câu mở đầu và kết thúc cho phim tài liệu "Chuyện tử tế."

PV: Nhân "Chuyện tử tế", anh nghĩ sao có ý kiến cho rằng làm người tử tế ngày càng khó?

Quả thật tôi cũng chưa bao giờ định nghĩa như nào là người tử tế. Nhưng chắc không đến nỗi khó khăn quá. Cố găng sửa mình trong hành vi có lẽ cũng là một cách để con người ta tử tế hơn. Có những điều mà mãi đến khi đi làm, tôi mới thay đổi hoàn toàn cách nhìn nhận. Ngày xưa những bà hàng bán cơm rượu khi vào các khu tập thể thường rơi vào cảnh bị "ăn cơm rượu hội đồng". Mỗi người thủ sẵn một cái muỗng, thi nhau "thử" nên chẳng mấy chốc là hết gánh cơm rượu! Người ta coi chuyện đó là bình thường, vì có một thời kỳ rất dài việc buôn bán bị xem là điều xấu xa, là kiếm lợi tức trên lưng người lao động, bóc lột.

Tôi nghĩ sự phát triển của loài người là nhờ thương mại. Nói cách khác thương mại là khởi nguồn văn minh. Lịch sử đã chứng minh những nơi có nhiều người giàu có là những nơi có thương mại phát triển. Sự giàu có của thành Troy là một điển hình. Thương mại liên quan đến nhiều lĩnh vực trong đời sống nhưng luôn bị đối xử bất công. Thương mại có thể phát triển ở những khu vực không có đầu tư, nhưng chắc chắn người ta ta sẽ không đầu tư ở những khu vực không có thương mại.

\section{PV: Sĩ, nông, công, thương. Trong suốt chiều dài lịch sử luôn bị xếp cuối cùng?}

Chúng ta chịu ảnh hưởng của Trung Quốc, nhất là Khổng Giáo. Đạo Khổng có công trong việc xây ra trường học, tạo nên một hệ thống lý thuyết và lan tỏa sâu rộng. Tuy nhiên, Khổng Tử là người không tiến bộ. Ông tin tuyệt đối vào những gì người xưa để lại, thể hiện rất rõ qua câu nói "Bất cải bất tắc" (không cải sửa, sáng tác). Điều đó rất nguy hiểm vì thời Khổng Tử chỉ có đến lễ nghi. Khổng Tử là nhà giáo có nhân cách lớn, nhưng thời của ông chưa có các phương pháp khoa học, ông lại tin tuyệt đối vào cái cũ thì làm sao mà phát triển được! Cũng chính vì không được cải sửa nên đã hình thành một hệ thống giáo dục theo kiểu thầy hơn trò, trò sau kém hơn trò trước... Như vậy là kéo lùi sự phát triển của xã hội. Trong khi ở Châu Âu khoảng thời gian đó có ba nhà triết học lớn là Aristotle, Plato và Socrates. Ba nhà hiền triết này theo đuổi trường phái biện chứng, chấp nhận tinh thần khoan hòa cái sửa và cổ vũ cho sự tranh biện. Socrate nói ông không viết sách vì ông không biết gì cả. Chính điều đó làm ông ấy trở nên thông thái. Mãi đến thế kỷ XIX, Nhật Bản là nước tiên phong ở khu vực châu Á chấp nhận cải cách hệ thống thi cử.

PV: Việc anh quyết định sang châu Âu du học liệu có phải là cách bày tỏ thái độ với giáo dục?

Không hoàn toàn như vậy. Tôi nghĩ rằng đi học cũng như đi du lịch, nếu cứ ở mãi một chỗ, thì sẽ không biết ở những nơi khác người ta gọi thế nào là món ngon. Lần sang làm việc ở Hy Lạp, sau khi tôi hoàn thành công việc, đối tác đã mời tôi đi ăn. Sau khi chén nhiều món hải sản, anh bạn Hy Lạp nói "bây giờ tôi mới cho ông biết thế nào là món ngon". Do vừa ăn xong những món rất ngon, nên tôi nghĩ món được giới thiệu đặc biệt này chắc phải "dữ dội" lắm. Người ta mang ra một dĩa trộn vàng vàng, đỏ đỏ, xanh xanh nhìn không biết là cái gì. Ăn vào không hề thấy ngon, mùi lại rất khó chịu, hỏi ra mới biết là món salad các loại phô mai. Điều tôi muốn nói ở đây là nếu chúng ta không biết chấp nhận những hệ quy chiếu khác thì làm sao biết những gì khác biệt với mình? Tôi không nghĩ chỉ có theo đuổi một nền giáo dục nước ngoài mới giúp chúng ta có khả năng suy nghĩ tốt hơn. Quan trọng là sự rèn luyện. Khi đọc về cuộc đời giáo sư Hoàng Tụy, tôi nhận ra rằng phần lớn kiến thức toán học của ông là do ông tự học qua những cuốn sách. Khi ra nước ngoài thì ông ấy đã nổi tiếng lắm rồi.

PV: Có suy nghĩ tốt, ý tưởng tốt nhưng nếu không có phương tiện, điều kiện vật chất thì cũng khó làm nên chuyện?

Đồng ý. Nhưng tôi nghĩ quan trọng nhất vẫn là khả năng suy nghĩ của con người. Nếu xét về mức độ tiêu tốn tài nguyên thì suy nghĩ ít tiêu tốn nhất. Suy nghĩ là thứ rẻ nhất mà con người có thể làm được. Người ta có thể nghĩ 
rất nhanh, rất nhiều trong khoảng thời gian ngắn. Trong mọi hoàn cảnh: lúc ngồi nhà ga, uống cà phê, trong phòng họp, khi ăn và kể cả lúc ngủ, người ta đều có thể suy nghĩ. Điều kiện vật chất để nghĩ không cần nhiều. Thậm chí cả một điều kiện tưởng như bắt buộc cũng không cần nốt, đó là bộ não. Chẳng hạn như Louis Pasteur, người phát minh ra vắc-xin chó dại, vi khuẩn bệnh than... Khi chết, khám nghiệm tử thi người ta mới biết là một nửa bộ não của ông ấy đã bị teo sau một cơn sốt xuất huyết, còn nửa kia liên tục bị phù nề và có thể gục xuống bất cứ lúc nào. Phần lớn phát minh của ông ấy ra đời sau khi một nửa bộ não đã bị teo. Khả năng tư duy của con người là vô cùng khủng khiếp. Mặt khác, người ta có quyền nghĩ sai và nghĩ lại trên cùng một đối tượng. Điều đó không thể áp dụng với ngôi nhà của bạn, nhưng với phép tính của bộ não thì được. Tôi nghĩ rằng đó là tiềm năng rất lớn mà chúng ta đang lãng phí. Thậm chí, phương tiện hiện đại như Internet có khi còn khiến bộ não người ta trở nên lười biếng. Vậy nên mới có thơ rằng: "Dân ta phải biết sử ta/ Cái gì không biết thì tra gúc gồ (trang web tìm kiếm Google)".

PV: Anh cũng "văn nghệ" nhi??

Tôi thuộc thơ kha khá.

PV: Có vẻ anh là người rất chịu khó đọc sách?

Tôi biết đọc sách từ khi còn bé xíu. Nguyên do là bố mẹ tôi đi làm thường nhốt tôi ở nhà và tủ sách gia đình là một trong những thú vui của tôi. Trong khu tập thể tôi ở có một người làm thủ thư, hàng tuần bác ấy đều đặn cầm về cho tôi một chồng sách, chủ yếu là truyện cổ tích. Cũng may là thời đó hoàn toàn không có "bụp - chát - hự" như sách dành cho thiếu nhi bây giờ. Tôi nghĩ điều tuyệt vời nhất của văn học là tạo ra trí tưởng tượng. Nhà bác học Albert Einstein nói rất hay rằng: "Tôi đủ tư cách để làm một nghệ sĩ bởi vì nghệ sĩ cần có trí tưởng tượng đủ lớn”. Thậm chí ông vẫn luôn coi kiến thức là hữu hạn, trí tưởng tượng mới là vô hạn... Không có trí tưởng tượng thì làm sao loài người có những phát kiến vĩ đại, làm sao phát triển như ngày nay.

Sau này viết sách, làm thống kê, tôi mới phát hiện ra rằng không có truyện cổ tích Việt Nam nào ca ngợi người giàu. Thường cứ nhắc đến người giàu thì nhân vật bao giờ cũng là phú ông, trọc phú và tên nhà giàu bóc lột. Còn đã khởi nghĩa thì bao giờ cũng có những đoạn cướp của người giàu chia cho người nghèo, ví dụ như trường hợp của nhân vật Quận He Nguyễn Hữu Cầu - lãnh tụ một cuộc khởi nghĩa nông dân dưới thời Lê - Trịnh. Lễ hội cũng vậy, chúng ta hàng năm có rất nhiều lễ hội về nông nghiệp, ngành nghề nhưng rất hiếm các lễ hội tôn vinh giới thương nhân. Đó là định kiến trải dài trong lịch sử, trở thành một phần của văn hóa. Khi xem giàu có là tội lỗi thì làm sao phát triển được.

PV: Nghĩa là trí tưởng tượng là phương tiện để phá vỡ những khuôn mẫu?

Tôi nghĩ trí tưởng tượng chỉ là sự khởi đầu. Còn để đi tiếp thì cần có lòng dũng cảm. Thống kê cho thấy từ thế kỷ thứ XVII đến nay, các thành tựu vĩ đại của loài người về phát triển kỹ thuật có liên quan đến khoa học đều không có công trình nào nằm ở châu Á.

PV: Người ta thường nói đến văn hóa kinh doanh. Còn anh lại dùng chữ văn minh...

Bản thân định nghĩa về văn hóa làbiatruoc.jpg, sinh ra các giá trị, theo đuổi những giá trị cốt lõi, lâu ngày sống lẩn quẩn với con người ta trở thành một phần của hệ thống tư duy. Tư duy vào một ngày đẹp trời nào đó sẽ điều khiển hành vi của con người. Trong văn hóa đấy, có những cái không tốt. Còn văn minh, trong cư xử xã hội là sự kiềm chế. Chẳng hạn như ở bàn bên cạnh (anh chỉ vào mấy đứa trẻ con người nước ngoài), ông bố đang làm dấu nhắc nhở những đứa con vì sự huyên náo mà chúng gây ra trong một không gian mà những người xung quanh cần sự yên tĩnh. Hành vi gây ra huyên náo đó là không kiềm chế. Trong kinh doanh, sự kiềm chế cũng có giá trị. Chỉ vì không hài lòng mà đập bàn, đứng dậy bỏ đi thì đó không phải là đối tác tốt. Tại sao không thể ngồi lại với nhau lâu hơn để tìm ra một tiếng nói chung. "Đừng bao giờ đóng sập cửa lại vì sẽ có lúc bạn muốn bước vào trong." 
Một khía cạnh khác của văn minh trong kinh doanh là hướng tới lợi ích chung của cộng đồng. Điều này giải thích tại sao có những người không mặc quần áo để phản đối sử dụng trang phục làm từ lông thú. Khi con người chưa sinh ra thì đã có thiên nhiên, người ta cho rằng việc bảo vệ thiên nhiên hoang dã là đảm bảo sự cân bằng của cuộc sống. Đó là chuyện con người với con thú, còn chuyện con người với con người thì xu hướng "dân chủ xã hội" đang thắng thế, chẳng hạn như ở Bắc Âu. Điển hình là hãng IKEA từ lâu đã không làm ăn với những doanh nghiệp sử dụng lao động trẻ em. Nếu chỉ xét lợi nhuận thuần túy thì lao động trẻ em là rẻ nhất, vì trẻ em không thể tự bảo vệ quyền lợi của mình như người lớn. Một khía cạnh khác, chủ doanh nghiệp nếu không văn minh, không yêu doanh nghiệp mình thì có thể bán sạch cổ phiếu đang nắm giữ khi giá đang sốt. Chuyện làm giàu tối đa và chuyện làm giàu một cách văn minh là rất khác nhau.

PV: Lý giải việc Việt Nam chưa có những doanh nghiệp trên 100 tuổi, anh nói nguyên nhân là do doanh nghiệp thiếu sức bền. Vậy theo anh, điều gì làm nên sức bền của một doanh nghiệp?

Tôi nghĩ quan trọng nhất là nền tảng văn hóa doanh nghiệp. Có một chuyện thế này. Ông Konosuke Matsushita vị Chủ tịch đầu tiên sáng lập Tập đoàn Matsushita - khởi nghiệp bằng việc sản xuất ổ cắm điện. Có thời điểm tập đoàn này kinh doanh thua lỗ, sắp phá sản, ông Matsushita lại... biến mất. Mọi người đổ đi tìm thì phát hiện ra ông ấy đang hí hoáy viết cái gì đó trong nhà kho. Hỏi ông viết gì, ông trả lời rằng đang ngồi viết cương lĩnh cho tập đoàn trong 250 năm. Không ai bảo ai, mọi người cười phá lên. Năm 2017, tập đoàn này sẽ kỷ niệm 100 năm thành lập!

PV: Ngoài công việc chính là kinh doanh, anh còn đi dạy. Liệu có quá ôm đồm?

Dù là phụ nhưng việc đi dạy cũng chiếm của tôi khá nhiều thời gian. Theo tôi, nghĩa vụ của người trí thức là chia sẻ. Thực sự thì việc dạy và làm của tôi cũng có quan hệ khá mật thiết với nhau. ở nước ngoài, để đứng trên bục giảng, tất cả giáo sư đều phải đi làm. Sự bắt buộc này là để đảm bảo sinh viên không phải tiếp thu kiến thức hạng hai. Tôi thường nói với sinh viên rằng chính các bạn ấy mới là người giỏi. Họ kém tôi nhiều tuổi nên khi tôi hết khả năng làm việc thì họ vẫn còn tiếp tục, phải vượt qua tôi. Đó là quy luật vận động của xã hội. Ngày làm luận án tiến sĩ, người hướng dẫn trực tiếp cũng đã từng nói với tôi ý tương tự.

\section{$P V:$ Bây giờ trò đã giỏi hơn thầy chưa?}

Chính vì câu nói của ông ấy mà tôi thấy mình dốt mãi.

PV: Còn với hai cô con gái nhỏ của anh. Con gái một vị tiến sĩ chắc phải học nhiều lắm?

ồ không. Tôi phản đối việc ép trẻ con học. Ngoài giờ học ở trường, trẻ cần có thời gian để vui chơi. Con gái lớn của tôi, mới chín tuổi, đang học tiếng Pháp nhưng nói tiếng Anh khá tốt, chủ yếu là nhờ chơi. Cháu vẽ tranh rất khá, được đăng báo mỹ thuật hẳn hoi. Năng khiếu đó tốt quá đi chứ. Có nhà khoa học thì cũng phải có người vẽ tranh, đó cũng là sự cân bằng.

PV: Ngày xưa anh cũng ham chơi?

Bốc đất bốc cát, câu cá câu ếch, đủ cả. Trẻ con bây giờ làm gì có cơ hội được chơi như thế hệ chúng tôi.

PV: Cảm ơn anh về cuộc trò chuyện thú vị này. 


\section{- Ba yếu tố làm nên thành công của doanh nhân}

29/07/2005 | Nguyễn Trần Bạt

\section{- Clip: Chúng ta luôn bên nhau}

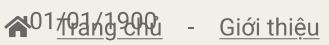

( ChungTa.com Hãy Đọc Sách

Tư liệu \& Suyngẫm

- Tư liệu \& Tra cứu

- Con người \& Nhân sinh

- Điều tra xã hội học

Giấy phép MXH: số 63/GXN-TTĐT

Đơn vị chủ quản: Công ty $\mathrm{CP}$ Chúng Ta Học

Đơn vị hỗ trợ vận hành: Hanoi Software JSC

Liên hệ: Minh Bùi - minhbui@chungta.com

Website được xây dựng trên nền tảng giải pháp mã nguồn mở VIEApps NGX microservices

(C) 2003 - 2021 ChúngTa.com

$\mathcal{S}$ vieapps.net viebooks.net tyrionguyen.com

\section{- Tác phẩm học làm người}

Tác phẩm

- Tác phẩm văn học

- Tác phẩm học thuật
Nhân vật

- Nhân vât Văn hóa

- Nhân vật Hoạt động Xã hội 


\section{TÀl LIẸU THAM KHẢO:}

[1] Nguyễn Văn Hữu, Vương Quân Hoàng. (2007). Các phương pháp toán học trong tài chính. NXB Đại học Quốc gia, Hà Nội.

[2] Vương Quân Hoàng, Ngô Phương Chí. (2000). Nguyên lý tài chính toán của thị trường chứng khoán. NXB Chính trị Quốc gia, Hà Nội.

[3] Vương Quân Hoàng. (2007). Văn minh làm giàu \& Nguồn gốc của cải. NXB Chính trị Quốc gia, Hà Nội. 